\title{
THE SMART STREET CANVAS: A VISUAL TOOL FOR SMART STREET IDEATION WORKSHOPS
}

\author{
Theo Lynn, Pierangelo Rosati and Grace Fox \\ Irish Institute for Digital Business, DCU Business School, Dublin, Ireland
}

\begin{abstract}
Shopping streets are an essential part of rural towns however after centuries of resistance to change, the resilience of rural shopping streets is being threatened by aging infrastructure, urbanization, online shopping, and now, COVID-19. In addition to connectivity, streets perform a number of important economic, social, and environmental functions. A smart street as a basic unit of urban space that leverages cyber-physical infrastructure to provide enhanced services to stakeholders, and through stakeholder use of the street, generates data to optimize its services, capabilities, and value to stakeholders. While there are a plethora of frameworks and tools for smart cities, these may be perceived as unwieldy, impractical and financially unfeasible at a town-level. This paper presents a prototype practical visual tool that can be used to help communities and local authorities develop, communicate and converge to a shared understanding of a smart street initiative in ideation workshops. The Smart Street Canvas is based on desk research and engagement with an Irish local authority, and reflects the challenges encountered on that project.
\end{abstract}

\section{KEYWORDS}

Streets, Canvas, Smart Streets, Smart City, Urban Planning

\section{INTRODUCTION}

The ubiquity, convergence, and advances in sensor, cloud computing, mobile and data science technologies are moving society towards one whose social structures and activities are increasingly organized around digital information networks that connect people, processes, things, data and social networks (Lynn et al, 2018). This is euphemistically called the "Internet of Everything" (IoE). It is a multi-trillion dollar opportunity worldwide for both the public and private sector. Significant Improvements to asset utilization and employee productivity, supply chain and logistics and accelerated innovation represent some of the benefits from increased connectivity (Bradley et al, 2013a; 2013b). For the general public, IoE heralds shortened product and service search times, an improved environment, better health outcomes, increased productivity, and overall improved quality of life. In the context of urban planning, the overwhelming focus of existing IoE research and policy on a global level is on cities. Notwithstanding this, so-called 'smart cities' do not necessarily have to be cities or technologies applied exclusively to cities, but can be any urban area seeking to use data to optimize operations (Harrison et al, 2010). Despite this, strategic initiatives using "smart city" technologies at a town-level have been hampered by a perception that existing frameworks, tools, and solutions for smart cities are unwieldy, impractical and financially unfeasible at a town-level. Consequently, there has been a small but growing focus on streets as a more generalizable, atomized, and as a result more manageable, unit of development (Přibyl and Přribyl, 2015).

For centuries, shopping streets in rural towns have been resistant to change. Today, these streets face an unprecedented number of challenges to their existence including aging infrastructure, increased competition from discount mass merchandisers, online shopping, increased urbanization, and now, COVID-19. In addition to connectivity, streets perform a number of important economic, social and environmental functions. Citizens undertake a wide range of mandatory, selective, and social activities on streets while they move through, rest, or conduct transactions in private premises on a street or within the public realm (Jung et al, 2009). Unlike much of society, streets have remained relatively immune to the current wave of digital transformation. This is partially due to the shared nature of streets, and specifically the public realm that makes up a significant portion of them. However, this lack of activity should not be confused with a lack of transformative potential. 
There is no reason for streets not to accrue many of the same benefits from digital transformation initiatives albeit at a reduced scale and local level.

A smart street is defined as a basic unit of urban space that (i) leverages cyber-physical infrastructure to provide enhanced services to stakeholders and through stakeholder use of the street, and (ii) generates data to optimize its services, capabilities, and value to stakeholders (Lynn et al, 2020a). We argue that a "street first" approach to smart city initiatives is both economically feasible and provides a basic building block upon which to develop further initiatives. Effective communication and stakeholder engagement are critical success factors in street design projects (GDCI, 2016). Unlike smart cities, there is a dearth of research on smart streets. As such, stakeholders in a community do not have the reference materials and tools to help shape and achieve a shared understanding for a smart street initiative. The value of visual tools for collaborating, communicating, and exploring new ideas and visions for organizations is well-established (Peters et al. 2020). One of the most popular visualisation tools is the Business Model Canvas (BMC) (Osterwalder et al, 2011). The BMC is widely used and reported benefits include perceived improvements in collaboration, teamwork, idea generation, conversations on strategy, the creation of a shared language amongst teams, structured practical outcomes to implement (Amarsy, 2015). The BMC has been adapted for a wide range of context including the smart city context (Giourka et al, 2019). Unfortunately, such frameworks and tools fail to recognize that due to governance and scale, towns have limited investment and policymaking capabilities and digital initiatives are often community-led multi-stakeholder initiatives and therefore become unwieldy and not particularly fit for purpose at the street level.

In this paper, we present a preliminary framework and visual tool, the Smart Street Canvas, to help communities and local authorities develop, communicate, and arrive at shared understanding of a smart street initiative through one or more ideation workshops. In line with Tsoukas and Chia (2002), the Smart Street Canvas is designed to be a discursive template that enables stakeholders notice and consider different components, see new distinctions and connections, and as a result, achieve a shared understanding. It is based on desk research and engagement with an Irish local authority, and reflects the challenges encountered on that project.

\section{SMART STREET CANVAS}

The design of the canvas draws on (i) academic and gray literature summarized in Lynn et al. (2020, 2020b), (ii) interaction with an Irish local authority and stakeholders in the development of a smart street proposal, and (iii) synthesis and development of the proposed framework outlined in Figure 1 below. While Blank (2016) adapted the BMC for mission-driven organisations through a process of relabeling, others have extended the BMC further with a specific focus on the value created by smart city technologies (Giorka et al. 2019). Like Giorka et al. (2019) our conceptualization of the Smart Street Canvas supports a multi-stakeholder collaborative effort. However, we explicitly recognize that (i) streets are a small and more manageable starting point to initialize smart city projects particularly for smaller urban areas, and (ii) the public realm is a central component of streets and, therefore, public authorities primarily fund such projects. As such, each component incorporates elements that public authorities typically need to address in funding decisions e.g. additionality, financial sustainability, policy alignment, impact and so on. The Smart Street Canvas comprises 18 components summarized in Figure 1 and described in Sections $2.1-2.18$ below.

\subsection{Rationale}

In the Smart Street Canvas, rationale refers to the motivation for the proposed project - the issues the project will seek to address or opportunities it seeks to capitalize on. Lynn et al (2020b) identify eight rationales for digital town projects adapted for smart streets (see Table 1 below). Smart streets may be motivated by one or more rationales depending on the current and existing use of the street and the town or city in which it is situated. 


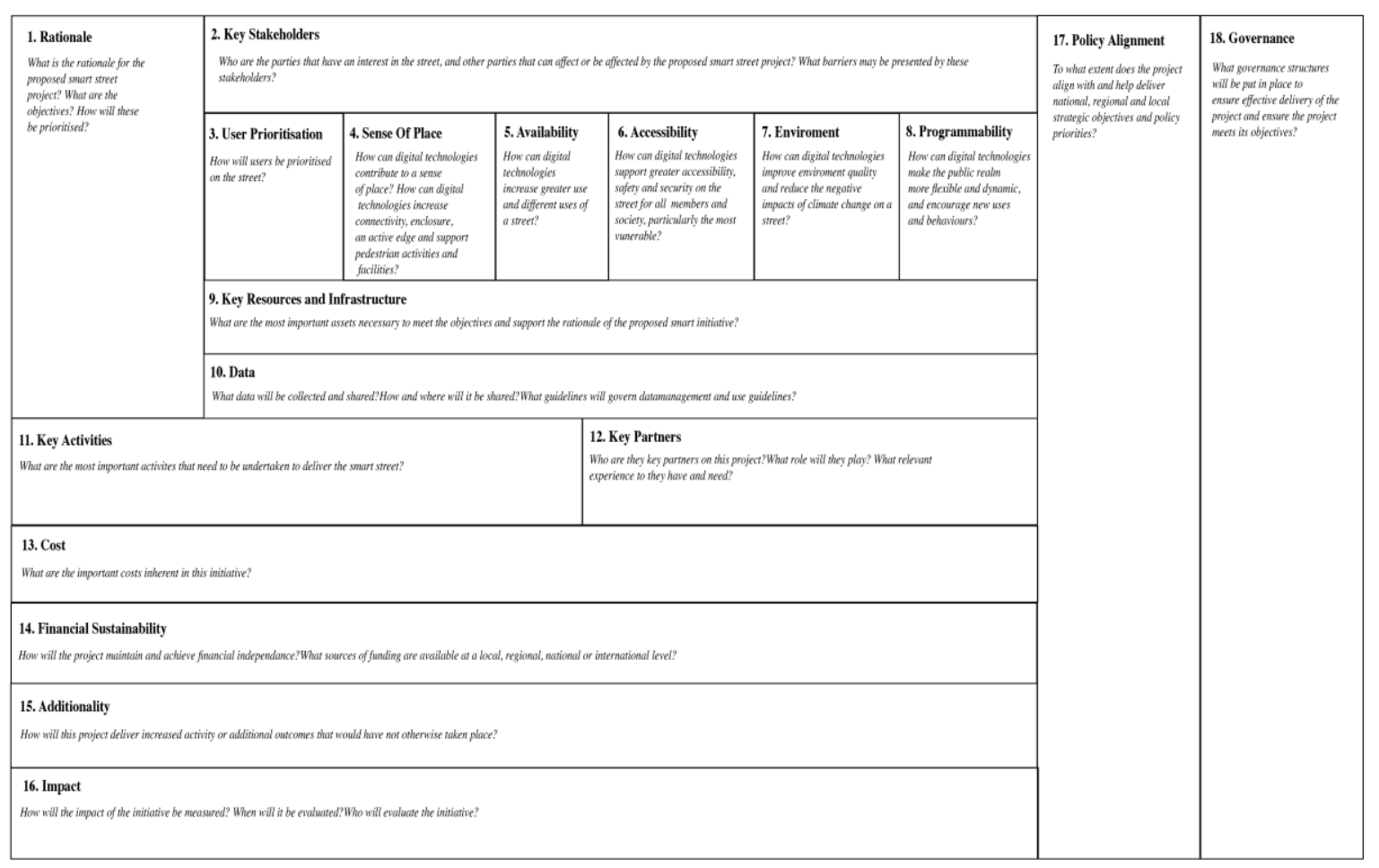

Figure 1. Smart Street Canvas

Table 1. High-level rationales for a smart street project (adapted from Lynn et al, 2020b)

\begin{tabular}{|c|c|}
\hline Rationale & Description \\
\hline Social & $\begin{array}{l}\text { Digital technologies can help users of a street participate and function more fully in a Digital } \\
\text { Society. }\end{array}$ \\
\hline Accessibility & $\begin{array}{l}\text { Digital technologies can increase accessibility, safety and security of those who may be } \\
\text { disadvantaged or vulnerable in society. }\end{array}$ \\
\hline Vocational & Digital technologies can help residents and users of a street prepare to work in a Digital Society. \\
\hline Sustainability & $\begin{array}{l}\text { Digital technologies can reduce adverse environmental impacts and build a resilient habitat for } \\
\text { existing and future residents on a street. }\end{array}$ \\
\hline Quality of Service & $\begin{array}{l}\text { Digital technologies can increase the range, quality and efficiency of service delivery including } \\
\text { public, commercial, and community services on a street. }\end{array}$ \\
\hline Catalytic & Smart streets can act as a catalyst for other innovations across a community. \\
\hline Economic & $\begin{array}{l}\text { The availability, quality, adoption and use of digital technologies may attract greater economic } \\
\text { growth and employment to a street and the businesses located on the street. }\end{array}$ \\
\hline Opportunistic & $\begin{array}{l}\text { Smart streets can differentiate a street and a town and may make it a more attractive place to live, } \\
\text { work or visit, or competitive from an economic and investment perspective. }\end{array}$ \\
\hline
\end{tabular}

\subsection{Stakeholders}

This refers the parties who have an interest in the street, and other parties that can either affect or be affected by the proposed project. It not only includes identifying who uses a street at the time of the exercise, how and when, but who might use it once the smart street project is operational. This is a wide range of stakeholder types including those with direct interests in the public realm (e.g., local authorities and utility companies etc.), private property owners and tenants, educational institutions, voluntary and social community organizations, and commercial businesses, but also users of the street. In order to meet the requirements of a diverse group of stakeholders, it is essential to fully understand the current barriers to change including apathy, fear, relevance, and inconvenience, and to design and select projects that seamlessly address these across a number of key themes using a combination digital and urban design interventions. As such, this section should include how stakeholders will be consulted and the benefits of the project communicated throughout the project. 


\subsection{User Prioritization}

Increasingly, urban planning emphasizes the need for more walkable communities for sustainability, public health, and social equity reasons. For example, both the Global Designing Cities Initiative (GDCI) and the Design Manual for Urban Roads and Streets (DMURS) follow a hierarchy of priorities, namely, pedestrians first, then cyclists, then public transport, then people doing business or carrying out public services on the street, and lastly, personal motorized vehicles (Lahart et al, 2019; GDCI, 2016). While such a "people first" strategy may be generally appropriate, other priorities may emerge depending on the rationale, stakeholders, the existing and desired sense of place, and proposed use cases.

\subsection{Sense of Place}

GDCI (2016) suggests that designing streets for place means considering the local culture and context. This includes the built and natural environment, the social and cultural context, and the economic environment. For DMURS (Lahart et al, 2019), sense of place while difficult to define has a number of attributes including:

- Connectivity - the creation of vibrant and active places requires pedestrian activity and consequently, should be walkable, connected and easily navigated.

- Enclosure - a sense of enclosure spatially defines streets and creates a more intimate and supervised environment.

- Active Edge - an active frontage enlivens the edge of the street creating a more interesting and engaging environment.

- Pedestrian Activity/Facilities - an enclosed street with an active edge creates a sense of intimacy, interest and overlooking and enhances a pedestrian's feeling of security and well-being.

Both GDCI and DMURS are derived from an urban design perspective based on a geographic rather than an information or cyber-physical space. For a smart street, one must consider what a digital analogue for this 'sense of place' might be and associated attributes. While in some cases, such as connectivity, the digital analogue is clear. For others, a deeper exploration of the role that digital technologies, and cyber-physical infrastructure as whole, can play in augmenting or reinforcing connectivity, enclosure, an active edge, and pedestrian activity and facilities may be required.

\subsection{Availability}

Availability refers to how digital technologies can be used to increase use of a street 24/7/365. Many locations experience weather conditions that may keep people indoors and lead them to choose to drive rather than walk or cycle. Furthermore, street design may exacerbate this behavior and adversely affect street use e.g. temporary or permanent obstructions, standing water etc. Combining urban design and digital technologies can increase the availability and use of streets. This may include designing zones in streets for more flexible and programmable use including programmable cycle lanes or pedestrianization. Similarly, weather mitigation strategies can be implemented so that the public can spend more time outdoors in the public realm, generating social, economic and public health outcomes that may otherwise be lost due to climate. Sensor nets can be implemented that monitor the street and inform local authority decisions.

\subsection{Accessibility}

Many streets, particularly older ones, can be challenging to vulnerable citizens including older people, and people with wheelchairs, visual difficulties or other impairments and people accompanying children with or without buggies/strollers. These include the existing street furniture, uneven or damaged surface dressing, lack of contrast between road and footpath surface dressing, poorly maintained hedges, and other temporary or movable obstructions. Digital technologies can increase accessibility and contribute to improved quality of life of all citizens, regardless of age, size and ability, by providing a safe and inclusive environment, and, as a result, increasing mobility thereby contributing to public health outcomes. For example, digital signals and beacon systems can be installed along the road that will provide audio or text messages to smart phones to alert those in need. Research suggests that benches to rest on and designing pavements and footpaths with clear 
separation of pedestrians and cyclists are high priority concerns for older citizens. Conversational technologies and interventions can be used to stimulate interaction with the public at large and specifically at risk communities. For example, AI-based conversational technologies built into smart furniture may provide "valuable practice" and coaching to help older adults navigate challenging conversations and improve both their health and quality of life (Razavi et al, 2019). Other research suggests that smart kiosks provide a vital bridge in crossing the digital divide by providing vulnerable communities with access to free Wi-Fi and public services and therefore support social inclusion (de Camargo Penteado et al, 2017).

\subsection{Environment}

Environment relates to environmental sustainability and how digital technologies and urban design can come together to make streets more environmentally sustainable, healthier and livable. Smart streets can provide communities with the opportunity for local actions to improve environmental sustainability and support awareness, education and adoption through urban design and technological innovation. For example, streets may prioritize roadbed use and parking space for pedestrians, cyclists, electric vehicles, and other sustainable practices. Reducing barriers to mobility including accessibility, security and safety measures can result in increased pedestrian use and reduced carbon emissions. Sensor networks, such as the University of Chicago Array of Things, can provide an urban measurement system and collect real-time data on the street's environment, infrastructure, and activity for research and public use (Array of Things, 2020). Sensors can monitor air quality, sound, and vibration, standing water, micro-climate, traffic as well as other activity on the street. This can be used to inform local decision making to reduce pollution and increase energy efficiency. The Internet of Things promises a wide array of green infrastructure including smart lampposts with energy efficient lighting and environmental sensing, solar and hybrid powered smart benches, intelligent pavement that harvests kinetic and solar energy to power on-street games and community challenges, lighting and other services, amongst others.

\subsection{Programmability}

A key challenge in urban design is to make streets, and specifically the public realm, more flexible and dynamic, and encourage both traditional and new uses of and behaviors in that space. Technology can be used to dynamically create time- and use-based flexible outdoor mixed-use spaces from wall to wall in the public realm. For example, digital infrastructure such as automated retractable bollards, digital signage, and embedded lighting in roadbeds can be used to prioritize cyclists or make an entire area pedestrianized in response to different triggers. Similarly, environmental sensors might trigger retractable awnings or alert local authorities of obstructions. This can be used to attract more footfall, social and ultimately commercial activity to the benefit of all stakeholders.

\subsection{Key Resources and Infrastructure}

As per the Business Model Canvas (Osterwalder et al, 2011) and Smart City Business Model Canvas (Giourka et al, 2019), key resources and infrastructure refers to the most important assets - physical, human, intellectual and financial - necessary to deliver the objectives and support the rationale for the proposed smart street project. In the context of a smart street, such resources and infrastructure typically include cloud storage, connectivity (network and power), smart street information systems, traffic and transit management, accessibility, security and safety, smart street furniture, weather mitigation, and green infrastructure.

\subsection{Data}

A street permeated by digital technologies will generate a significant amount of data from the smart objects on the Street and active and passive user interaction with those objects. Project sponsors need to decide whether and how that data will be made available, and how proposed use of data will be approved and governed. The EU considers open data a critical component of the overall EU data economy and can (i) stimulate economic growth and spur innovation, (ii) help address societal challenges with the development of innovative solutions, 
(iii) enhance evidence-based policymaking and increase efficiency in public administrations; (iv) become a critical asset for the development of new technologies including AI, and (v) foster greater participation of citizens in political and social life and increase government transparency (European Commission, 2020).

\subsection{Key Activities}

Again, as per other canvases (Osterwalder et al, 2011; Giourka et al, 2019), key activities relate to those activities that need to be undertaken to deliver, manage and maintain the smart street. This includes a combination of urban planning, stakeholder engagement, civil engineering, ICT evaluation and implementation, procurement, evaluation etc.

\subsection{Partners}

Partners refer to the key actors including public authorities and agencies, suppliers, and vendors essential for the development and maintenance of the smart street project.

\subsection{Cost Structure}

Cost structure refers to the key cost by type - once-off, recurring, fixed and variable - to deliver and maintain the smart street over a specific period of time. Public funding will often require a breakdown by cost category including salaries and administration costs, building or site purchase, refurbishment and renovation costs, equipment and fit-out, professional and legal fees, as well as contingency. Marketing and outreach costs should also be considered. In the context of a smart street, it is critically important to identify civil engineering and ICT costs separately as the useful working life of such investments is significantly different.

\subsection{Financial Sustainability}

Financial sustainability refers to how the project will achieve and maintain financial independence once established. Traditionally, the public realm is maintained by a public sector agency or local authority however such infrastructure is typically longer lasting than the ICT components in a smart street, which may need more regular maintenance or replacement. As such, project initiators must consider how this will be funded. Potential alternative funding models include usage fees, concessions, advertising, sponsorship, and other service fees, energy trading, public private partnerships, and crowdfunding.

\subsection{Additionality}

Analysis from other projects (see, for example, EIP-SCC, 2017) suggests smart infrastructure, and in particular urban data platforms, e-bike and smart lamp post initiatives, are simply not possible without public financing. Indeed, $40 \%$ of those surveyed reported that between $77 \%$ and $92 \%$ of funding came from local (40\%), EU or national grants (34\%), or other sources, many of which were public funds. $8 \%$ of initiatives were funded or expected to be funded by the market. The trend for smart public realm infrastructure in the EU would seem to be predominantly public sector owned and operated $(60 \%)$, mixed forms of public and private partnership and collaboration (22\%), concession/private service providers $(10 \%)$, and utility owned and operated $(8 \%)$. While some smart city initiatives are in smaller towns, the overwhelming majority are in cities whose authorities have significant income generation capacity themselves. Without a significant injection of public funds, smart street projects simply are less likely to take place. As such, sponsors of smart street initiatives need to be able to elucidate how public funding into a smart street will deliver increased activity or additional outcomes that would not otherwise take place including unlocking other funding sources e.g. for research or industrial testing. 


\subsection{Impact}

Measuring and communicating impacts of smart street interventions helps inform better decisions on resource allocation but also communicate progress to policymakers and the community, thereby building both political and community support for future funding and other projects. As per GDCI (2016), we suggest that for the purposes of ideation workshops, smart street projects should focus on three categories:

- Cyber-physical and operational changes: short-term quantitative results on progress towards meeting cyber-physical infrastructural targets (e.g., new or improved facilities, technologies or infrastructure).

- Shifts in use and function: medium-term quantitative and qualitative results on how the street is used differently as a result of the project (e.g., changes in behavior, new users of street or the cyber-physical infrastructure), changes in transit flow and type, and improved functions (e.g., energy efficiency, walkability, service access).

- Resulting impacts - long-term cyber-physical physical, operational, and functional changes that impact the overall performance of the street, and whether the investment and associated implementation is achieving the desired outcomes.

The specific outcomes should relate to the rationales and objectives of the projects. For example, economic outcomes may include changes in employment (once-off, recurring, direct and indirect), increased retail turnover, property values and rents, tourism-related spending. Wider social impacts may include increased quality of life resulting from greater mobility and accessibility, reduced carbon emissions and energy costs, and other neighborhood effects. In addition, a timeframe for impact should be indicated.

\subsection{Policy Alignment}

As smart street projects are likely to require public sector funding and support, the extent to which the project can support or deliver local, regional and national strategic policy plans, objectives and priorities. A mapping of smart street interventions against such policies can help identify funding, partners, and supporters.

\subsection{Governance Structure}

As discussed in Section 2.14, a smart street project is likely to include a substantial investment from the public sector. As such, a governance structure will be required to ensure the effective delivery of the project on-time and within budget including mechanisms for financial oversight, accountability, and compliance with regulations will be required. Furthermore, the governance structure should include mechanisms for the ongoing management, maintenance and development of the smart street infrastructure and the evaluation of the project against its goals.

\section{FUTURE WORK}

This paper presents a new visual tool and discursive template for stakeholders to co-create and achieve a shared understanding around a smart street initiative. Given the relative nascency of smart streets as a concept in academic literature, it makes an early contribution as an artefact. Similarly, from a practitioner perspective, it provides a practical tool for stakeholder engagement and ideation based on our real-world experience of scoping a smart street initiative for a rural town.

This is a first iteration of the Smart Street Canvas and thus requires further validation and rigorous testing in practice. It was designed in the context of a shopping street in an Irish rural town. While we believe it is applicable in other urban contexts and street types, this requires further investigation. Furthermore, it is not envisaged as a standalone tool. Work is currently ongoing to develop additional tools for mapping and visualizing existing street user journeys and experiences and envisioning how digital technologies can be used to improve those journeys and experiences. In addition, there is a lack of knowledge about the potential elements of a smart street. As such, we are cataloguing and categorizing potential smart street interventions and developing case studies that can both inspire and educate stakeholders on the potential of smart streets. 


\section{ACKNOWLEDGEMENT}

This work is partially funded by Wexford County Council and by the Irish Institute of Digital Business.

\section{REFERENCES}

Amarsy, N.,2015. Why and how organizations around the world apply the Business Model Canvas. Strategyzer.

Array of Things, 2020. Array of Things. Available at: https://arrayofthings.github.io/ (last accessed on 14 December 2020).

Blank, S., 2016. The Mission Model Canvas-An adapted Business Model Canvas for mission-driven organizations. Available at: https://steveblank.com/2016/02/23/the-mission-model-canvas-an-adapted-business-modelcanvas-formission-driven-organizations/ (last accessed on 03 February 2021).

Bradley, J., Reberger, C., Dixit, A. and Gupta, V., 2013. Internet of everything: A \$4.6 trillion public-sector opportunity. Available at: https://www.cisco.com/c/dam/en_us/about/business-insights/docs/ioe-public-sector-vas-white-paper.pdf (last accessed on 14 December 2020).

Bradley, J., Barbier, J. and Handler, D., 2013. Embracing the Internet of everything to capture your share of \$14.4 trillion. Available at: https://www.cisco.com/c/dam/en_us/about/ac79/docs/innov/IoE_Economy.pdf (last accessed on 14 December 2020).

de Camargo Penteado, C.L., de Souza, P.R.E., Fortunato, I. and da Silveira, S.A., 2016. Connectivity Public Policy in the Network Society: The Case of "WiFi Livre SP. Communication and Information Technologies Annual (Studies in Media and Communications), Vol. 12., pp. 299-314.

EIP-SCC, 2017. Humble Lamppost Survey Insight Paper. Available at: https://eu-smartcities.eu/node/11290 (last accessed on 14 December 2020).

European Commission, 2020. Open Data. Available at: https:/ec.europa.eu/digital-single-market/en/open-data (last accessed on 14 December 2020).

Giourka, P. et al, 2019. The smart city business model canvas-A smart city business modeling framework and practical tool. Energies, Vol. 12, No. 24, pp. 1-17.

Harrison, C. et al, 2010. Foundations for smarter cities. IBM Journal of research and development, Vol. 54, No. 4, pp.1-16.

Global Designing Cities Initiative, 2016. Global street design guide. Island Press, Washington D.C., USA.

Jung, S.W., Lee, J.K.J. and Ha, J.M., 2009. A Study on Analysis of User Behavior in Urban Central Street: On the Dongsung Street in Daegu. Journal of the Regional Association of the Architectural Institute of Korea, p. 300.

Lahart, J. et al, 2019. Design manual for urban roads and streets. Irish Department of Transport, Tourism and Sport and Irish Department of Housing, Planning and Local Government. Available at: https://www.housing.gov.ie/planning/guidelines/urban-roads-and-streets/design-manual-urban-roads-and-streets-lowres (last accessed on 14 December 2020).

Lynn, T., Rosati, P. and Endo, P., 2018. Towards the Intelligent Internet of Everything: Observations on Multi-disciplinary Challenges in Intelligent Systems. Proceedings of the Research Coloquio Doctorados: Tecnología, Ciencia y Cultura: una visión global. Puebla, Mexico, pp 1-9.

Lynn, T., Rosati, P. and Fox, G., 2020a. Smart Streets: Definition, Principles, and Infrastructural Elements. ICDS 2020: The Fourteenth International Conference on Digital Society. Valencia, Spain, pp. 1-10.

Lynn, T. et al, 2020b. Addressing the Urban-Town-Rural Divide: The Digital Town Readiness Assessment Framework. ICDS 2020: The Fourteenth International Conference on Digital Society. Valencia, Spain, pp. 1-10.

Osterwalder, A., Pigneur, Y., Oliveira, M.A.Y. and Ferreira, J.J.P., 2011. Business Model Generation: A handbook for visionaries, game changers and challengers. African journal of business management, Vol. 5, No. 7, pp.22-30.

Peters, D., Loke, L. and Ahmadpour, N., 2020. Toolkits, cards and games-a review of analogue tools for collaborative ideation. CoDesign, pp.1-25.

Přibyl, P. and Přibyl, O., 2015. Definition of a smart street as smart city's building element. In 2015 Smart Cities Symposium Prague (SCSP), Prague, Czech Republic, pp. 1-6.

Razavi, S.Z., Schubert, L.K., Van Orden, K.A. and Ali, M.R., 2019. Discourse Behavior of Older Adults Interacting with a Dialogue Agent Competent in Multiple Topics. arXiv preprint arXiv:1907.06279.

Tsoukas, H. and Chia, R., 2002. On organizational becoming: Rethinking organizational change. Organization science, Vol. 13, No.5, pp.567-582. 